\title{
BMJ Open Exploring the impact and experience of fractional work in medicine: a qualitative study of medical oncologists in Australia
}

$\overline{\text { Emma Kirby (D) , }{ }^{1} \text { Alex Broom, }{ }^{2} \text { Deme Karikios, }{ }^{3,4} \text { Rosemary Harrup, }{ }^{5} \text { Zarnie } \text { Lwin }^{6,7}}$

To cite: Kirby E, Broom A, Karikios D, et al. Exploring the impact and experience of fractional work in medicine: a qualitative study of medical oncologists in Australia. BMJ Open 2019;9:e032585. doi:10.1136/ bmjopen-2019-032585

- Prepublication history and additional material for this paper are available online. To view these files, please visit the journal online (http://dx.doi org/10.1136/bmjopen-2019032585).

Received 26 June 2019 Revised 03 November 2019 Accepted 11 November 2019

Check for updates

(C) Author(s) (or their employer(s)) 2019. Re-use permitted under CC BY-NC. No commercial re-use. See rights and permissions. Published by BMJ.

For numbered affiliations see end of article.

Correspondence to

Dr Emma Kirby;

emma.kirby@unsw.edu.au

\section{ABSTRACT}

Objectives Fractional (part-time) appointments are becoming more commonplace in many professions, including medicine. With respect to the contemporary oncological landscape, this highlights a critical moment in the optimisation of employment conditions to enable highquality service provision given growing patient numbers and treatment volume intensification. Data are drawn from a broader study which aimed to better understand the workforce experiences of medical oncologists in Australia. This paper specifically aims to examine a group of clinicians' views on the consequences of fractional work in oncology.

Design Qualitative, one-on-one semistructured interviews. Interview transcripts were digitally audio recorded and transcribed verbatim. Data were subject to thematic analysis supported by the framework approach and informed by sociological methods and theory.

Setting New South Wales, Australia.

Participants Medical oncologists ( $n=22)$, including 9 female and 13 male participants, at a range of career stages.

Results Four key themes were derived from the analysis: (1) increasing fractional employment relative to opportunities for full-time positions and uncertainty about future opportunities; (2) tightening in role diversity, including reducing time available for research, mentoring, professional development and administration; (3) emerging flexibility of medical oncology as a specialty and (4) impact of fractional-as-norm on workforce sustainability and quality of care.

Conclusion Fractional appointments are viewed as increasing in oncology and the broader consequences of this major shift in medical labour remain unexamined. Such appointments offer potential for flexible work to better suit the needs of contemporary oncologists; however, fractional work also presents challenges for personal and professional identity and vocational engagement. Fractional appointments are viewed as having a range of consequences related to job satisfaction, burnout and service delivery. Further research is needed to provide a critical examination of the multiple impacts of workforce trends within and beyond oncology.

\section{BACKGROUND}

A career in medicine has always been competitive, from acceptance into medical school through to acceptance into training
Strengths and limitations of this study

- Use of in-depth interviews to elicit rich data on health professionals' experiences and perspectives on fractional work in medicine, and the benefits and challenges therein.

- Qualitative data may help to better understand changing professional expectations and priorities at both individual and institution/system levels.

- Qualitative data may be critical to better understand professional's views on medical labour more broadly, and the implications of new forms of practice, and new career pathways, for workforce sustainability.

- This study is exploratory in nature and professionals' experiences and perspectives on fractional appointments in medicine may differ across settings/ contexts.

- The Australian healthcare system has considerable variability across contexts and geographical settings, and the issues and challenges across settings are difficult to completely capture in a small qualitative sample.

programme and specialty areas. ${ }^{1-5}$ Yet underlying this competition has been the idea that medicine provided career security. ${ }^{2} 67$ In recent years, a range of workforce issues (eg, increasing patient loads, high competition for public hospital job opportunities, superspecialisation and intensification of work more broadly) have combined to change the very character of medical work within and beyond oncology. ${ }^{6-19}$ The traditional 'safety' of the full-time, permanent physician or surgical position within the public hospital system has been eroded in favour of more flexible working arrangements and/or diversified options, ${ }^{14} 18$ or as a clinical fraction of a 'portfolio career'. ${ }^{520}$ Thus, fractional appointments —regular ongoing/permanent or contracted appointments which consist of a fraction of a full-time workload (1FTE—full-time equivalent)—are becoming 
more visible and commonplace within hospital settings in higher income countries (HICs).

Expectations for oncology work in HICs are shifting. Recent studies within and outside oncology have identified demands for higher level qualifications and research expertise. $^{6} 11131921-24$ Other studies, meanwhile, have begun to highlight workforce concerns around diminishing opportunities for mentorship and career prospects, job satisfaction and increased burnout. ${ }^{111314212526}$ These studies point to the need for renewed focus on individual work adaptive experiences and workforce sustainability. Understanding the experiences of the workforce is integral in maintaining an efficient and productive medical oncology profession at a time of ever-increasing challenges for the provision of quality cancer care. ${ }^{151921222627}$ However, little is known about the changing nature of appointments within oncology, nor how they are perceived within the workforce.

Fractional work-consisting of single or multiple parttime appointments-may offer significant flexibility for a career in contemporary medicine. Potential benefits include balancing work hours with other commitments, working without traditional institutional commitments including service roles, the capacity to work for a range of employers and/or through freeing up time to pursue and/or balance private practice as well as public. ${ }^{28}$ Part-time appointments may also be attractive for those working within specialty areas prone to burnout, ${ }^{15} 23$ and for women (and men with primary carer responsibilities). ${ }^{3} 15161929$ Control over (and fewer) work hours has been shown to be associated with greater job satisfaction, ${ }^{3} 112126$ better work-life balance ${ }^{1023}$ and better lifestyle. ${ }^{10}{ }^{30}$ Put simply, fractional appointments may hold considerable potential for supporting conditions which better suit work-life well-being. ${ }^{29}$ Part-time work can also bring challenges. Fractional staff may be positioned on the margins in terms of status, institutional involvement or engagement, and part-time clinicians may be segregated, widening the gap between particular forms of work (eg, clinical, teaching and research roles).$^{24}$ Thus, the aim of this article is to report the experiences of a group of medical oncologists working in Australia, to better understand perspectives on fractional appointments, and on medical labour more broadly, within the oncological context.

\section{METHODS}

\section{Data collection and sample}

The analysis reported below is part of a broader study which explored the experiences and expectations of Australian medical oncologists, and the implications for the present and future viability of provision of medical care within oncological settings. The broader study objective was to gain a comprehensive understanding of the experiences of medical oncologists in the current workforce, including key insights into barriers to and enablers of career opportunities in the context of current policy and cancer care. ${ }^{11}{ }^{1314}$ We note here that the Australian health care system consists of a two-tiered model of public and private health care. For doctors in public employment (i.e government hospitals), individual states and territories have an Award system which clearly details allowance, hours or work, leave benefits such as study leave, professional development leave, maternity andparental leave for full time and part-time employees. Finer details of the Award conditions vary across the states and territories. Moreover, within each state, workforce context often differs in city, regional or remote settings. Informed by interpretivist sociological perspectives to research design and analysis, we employed an inductive approach to data collection, using qualitative in-depth interviews. Following university ethics approval, an email was sent to New South Wales-based medical oncologists using the membership list of the Medical Oncology Group of Australia (MOGA) (the lead representative body for medical oncologists in Australia, MOGA membership is optional, includes advanced trainees and qualified medical oncologists, and comprises greater than $80 \%$ of the medical oncology workforce, including trainees). MOGA has over 600 members, and New South Wales accounts for $34 \%$ of membership. This email invitation included an information sheet and consent form detailing the aim of the study and participation requirements. Potential participants were asked to contact a research team member to register their interest. Sampling was informed by snowball and convenience sampling strategies, ${ }^{31}$ with participants also recruited through colleagues who were either themselves participating or were aware of the study. All those who indicated an interest were interviewed, and during the early stages of data collection, preliminary analysis began. We conducted rounds of initial analysis through several team meetings, sharing note taking and discussion between three research team members, to guide ongoing sampling. This involved sharing ideas that were identified in the data, early development and discussion of themes. Following several rounds of analysis, the researchers agreed that data saturation had been reached-namely, we reached the point when no new themes were identified relating to the focal areas of study ${ }^{32}{ }^{33}$ At the beginning of each interview, participants were reminded of the study aims, and afforded the opportunity to ask questions, before giving written or verbal informed consent. The interviews were conducted during 2015 by one university-based research team member experienced in social science research and qualitative interviewing techniques, at locations convenient for the participant (eg, their workplace), lasted between 60 and $90 \mathrm{~min}$, and were digitally audio recorded and transcribed in full by a professional transcribing company. Interviews were semistructured and guided using a topic guide (see online supplementary appendix 1) focused on participants' work-related experiences (eg, workforce-related issues, patient issues). While the interviews did not specifically focus on fractional appointments, participants focused on this perceived workforce trend; the research question 
and findings addressed in this article are thus inductively derived from the analysis of participants' accounts.

\section{ANALYSIS}

A systematic thematic analysis was conducted, driven by a framework approach,${ }^{34}$ using NVivo 11 software as a data management tool. We employed the following steps: (1) familiarisation: researchers reviewed the transcripts. (2) Identification of framework: key themes were identified around which the data were organised. (3) Indexing: application of themes to text: labelling and arranging each text excerpt, word, term, or research note related to each participant, producing lists including data and notes from several participants according to themes. (4) Charting: headings and subheadings were used to build an overall picture of the data. (5) Mapping and interpretation: associations were clarified, and explanations developed. This involved finding associations between and within themes and moving towards and developing explanations for the findings in line with our research aims. ${ }^{32}$ Independent coding of the data was provided initially by two members of the research team, which was then discussed with two other team members during several team meetings, to crosscheck codes and further develop themes. ${ }^{35}{ }^{36}$ Analytic rigour was enhanced by searching for negative, atypical and conflicting or contradicting cases in theme development. ${ }^{32} 3536$ Audio recordings, transcripts, coding reports and notes were retained along with documentation detailing the research aims, design and sampling, and recruitment processes and practices to provide an audit trail. The Standards for Reporting Qualitative Research checklist was used to ensure comprehensive reporting. ${ }^{37}$

\section{RESULTS}

We conducted interviews with 22 medical oncologists at different stages of their careers and working in both major city and inner regional settings. Fifteen participants were working in full-time equivalent positions, among them eight were advanced trainees. Seven participants were in single or multiple fractional appointments, including private practice and/or research (university paid) positions. Participant characteristics are presented in table 1. We derived four predominant themes from our analysis around the character and place of fractional appointments for the medical oncology workforce: (1) increasing fractional work relative to opportunities for 1FTE positions and uncertainty about future opportunities; (2) the tightening and restricting of diverse rolesfractional appointments associated with clinic time (and reducing time available for research, teaching/learning and administrative work); (3) the emerging flexibility of medical oncology as a specialty and the attraction of fractional appointments (for some); and (4) the impacts of fractional as norm on workforce sustainability and quality of care. A summary of key themes and indicative examples is included in table 2.

\begin{tabular}{ll}
\hline Table $\mathbf{1}$ Characteristics of the sample & \\
\hline Characteristic & $\mathbf{n = 2 2}$ \\
\hline Sex & \\
$\quad$ Female & 13 \\
Male & \\
Career stage & 8 \\
Advanced trainee & 6 \\
Early career oncologist & 8 \\
Senior consultant & \\
Location & 19 \\
City & 3 \\
Regional & \\
Appointment type & 15 \\
Full time & 7 \\
Fractional (single or multiple part-time \\
appointments)
\end{tabular}

Increasing fractional appointments: uncertainty and lack of full-time equivalent job opportunity

The widespread awareness within the workforce of the increasing proportion of fractional appointments relative to new full-time equivalent appointments within the public hospital system was clear from the interviews (indicative quotations shown in table 3). Indeed, talk of the 'future' of the medical oncology workforce, both broadly speaking and for individual's future career considerations, was dominated by issues around fractional appointments, and the consequences therein. Fractional appointments were often talked about as part-time employment; however, at times, fractional appointments were also viewed as components of full-time work. That is, that fractional appointments might be seen as a set of building blocks to cobble together a full-time equivalent load. Full-time positions were certainly viewed as 'under threat', with a trend towards replacing retiring full-time staff with one, two or three fractional positions frequently flagged by participants as occurring within their own institutions. Given that full-time appointments were viewed as increasingly unusual or rare, participant's accounts within the interviews often turned towards the perceived burdens and benefits of fractional work. Moreover, the interviews highlighted consensus that attaining a traditional full-time role was increasingly unrealistic, but also that within oncology, such traditional full-time roles retain status and credibility, given their difficulty to attain.

\section{Tightening and restricting of diverse roles: fractional work as 'clinic focused'}

As shown in the indicative quotations in table 4, participants reflected on the specificities of roles and tasks within everyday contemporary medical oncology work. All participants, in describing fractional appointments, talked about the distinction between day-to-day work and everything else. Day-to-day work referred to clinical 
Table 2 Summary of key themes

\begin{tabular}{|c|c|}
\hline Theme & Example \\
\hline Increasing fractional appointments & $\begin{array}{l}\text { Uncertainty around future prospects } \\
\text { Perceived lack of full-time equivalent job opportunity } \\
\text { - Unrealistic to expect a traditional full-time role } \\
\text { - Fractional work as entailing benefit and burden }\end{array}$ \\
\hline Tightening and restricting of diverse roles & $\begin{array}{l}\text { Fractional work as 'clinic focused' } \\
\text { - Fewer opportunities for teaching, research, administrative or institutional } \\
\text { responsibilities } \\
\text { - Less capacity for mentoring, professional development, peer support within } \\
\text { paid hours } \\
\text { Additional pressure to build a career in creative/unpaid ways }\end{array}$ \\
\hline $\begin{array}{l}\text { Emerging flexibility of oncology as a } \\
\text { specialty }\end{array}$ & $\begin{array}{l}\text { Fractional appointments as attractive (for some) } \\
\text { Opportunity to pursue other (non-clinical) areas of interest } \\
\text { Supportive option for those with caring responsibilities } \\
\text { Potential penalties: less opportunity for career advancement } \\
\text { Imbalance of responsibilities; compensating for full-time or part-time employee } \\
\text { loads }\end{array}$ \\
\hline $\begin{array}{l}\text { Fractional appointments and 'the healthy } \\
\text { triangle' }\end{array}$ & $\begin{array}{l}\text { Importance of engagement in clinical work, research and teaching } \\
\text { Impacts of fractional work on workforce sustainability including career security, } \\
\text { job satisfaction, avoiding burnout } \\
\text { Consequences for quality of care provided to patients } \\
\text { Need for investment, contribution and loyalty to institutions, health services and } \\
\text { patients }\end{array}$ \\
\hline
\end{tabular}

practice, with fractional work described as dominated by outpatient clinic hours. Everything else referred to all of the non-clinic-based tasks or responsibilities of a specialist hospital clinician. These included teaching, research (including data collection, lab work, publishing and conference attendance) administrative/institutional responsibilities, service to the profession, mentoring, other professional development, peer support and so on.
The distinction between day-to-day work and everything else was inextricably linked to perceptions of workload, with the 'everything else' part of a career in oncology talked about as much more difficult to engage with for those in fractional appointments. Non-clinic-based tasks and roles were repositioned within several participant's accounts as voluntary, pushed outside the paid hours of employment. Yet such volunteer roles within oncological

Table 3 Indicative quotations: increasing fractional appointments

\begin{tabular}{ll}
\hline Participant & Indicative quotation \\
\hline \#10, Male, Consultant & $\begin{array}{l}\text { I think, that a big challenge for academic oncology is that the staff specialist positions for medical } \\
\text { oncologists are disappearing. Also the idea of full-time salaried positions in public hospitals for } \\
\text { medical oncologists is disappearing. They're becoming more and more part-time. }\end{array}$ \\
$\begin{array}{l}\text { \#13, Female, Early } \\
\text { Career }\end{array} \begin{array}{l}\text { You have to be just flexible if you want a job. So my viewpoint is if a fraction came up anywhere that } \\
\text { desperate we are for jobs. }\end{array}$
\end{tabular}

\#19, Female, Consultant I think within medical oncology, there's a huge job shortage at the moment and I can only see it becoming a bigger problem. I certainly see with my colleagues that it's becoming more unusual for people to be appointed as a full-time position anymore. People are taking fractionated positions, doing some clinical work here, maybe some research there, different affiliations with the universities. So I think we've got a lot more fractional positions. We've probably got a lot more people working in part-time capacities... Yeah, there are a lot of people out there doing diverse things whilst waiting for that elusive job and when that job comes up, it's very unusual that it's going to be a full-time position. It may well be 0.4 doing this 0.6 here. I think it's a lot more fractional now.

\#21, Male, Early Career There are few opportunities in the public system for the good old full-time staff specialist thing. That doesn't really exist anymore.

\#16, Male, Consultant So what happens is that hospital appointments get fractionated. So someone who was on full-time capacity, when they retire they break their job into three positions, $0.4,0.4$ and $0.2 \ldots$ I can give you 20 names of people who've finished training and they don't have a real [full time] job. 
Table 4 Indicative quotations: tightening and restricting of diverse roles

\begin{tabular}{|c|c|}
\hline Participant & Indicative quotation \\
\hline \#10, Male, Consultant & $\begin{array}{l}\text { The expectation is that they come in and work their bums off in the outpatients [clinics] for a } \\
\text { couple of days and then go and earn squillions outside in private practice, and what that drives } \\
\text { is people away from the things that I think are so important, that is engagement in research and } \\
\text { training, because they end up just being forced financially and from every other respect to be full- } \\
\text { time consulting clinicians and I worry a lot about that because I think of all the things that's kept } \\
\text { me sane, it's been the luxury of being able to spend a portion of my life doing that hard consulting } \\
\text { work but another, perhaps, two and a half days a week away from that where I'm doing academic } \\
\text { things, teaching, researching. Those positions are disappearing and that's a massive problem for } \\
\text { the profession here in the next ten years. }\end{array}$ \\
\hline $\begin{array}{l}\# 11 \text {, Female, Advanced } \\
\text { Trainee }\end{array}$ & $\begin{array}{l}\text { I feel like there's a lot of pressure to get involved in research. I'm trying to juggle a few projects at } \\
\text { the moment, and everyone's sort of doing projects and you hear about projects other people are } \\
\text { doing and this one's doing three, that one's doing four, this one had theirs published like in the top } \\
\text { oncology journal and it's, yeah, there's a lot of expectation to get involved in research. I appreciate } \\
\text { that because we do, there is so much research and I think to know how to interpret research, you } \\
\text { need to be involved in it firsthand but it's an extra layer of work to what you do on a day-to-day } \\
\text { basis. }\end{array}$ \\
\hline
\end{tabular}

\#4, Female, Consultant

So for example, I get a lot of junior staff, 'cause we advertise for fellowships here, who, in their second year of advanced training and they'll ask, "Ah, there's no jobs. What am I going to do? There's no jobs in the public system. I really want a public hospital position in Sydney." Everyone wants that. And you just go, "Well, they're not available. Think outside the box. A lot of people have cancer, cancer is going up, treatments are going up, there are a lot of opportunities if you would think outside the box. There are private facilities, there's this, there's that. Build it, build what you want. Start here, start there," and it's never occurred to them to think any differently. [emphasis added]

\#21, Male, Early Career

The other thing...that's changing is with the fractional staff specialist appointments now, my perception is there's a general attitude that public hospital positions are being seen more and more as service provision for clinical care and less time set aside for research, education, teaching whereas the traditional full-time jobs usually had a clinical load but did have designated times to do research, and I think they're sort of being slashed and burned a bit and it's all about seeing people at the coalface and treating, and all your research has to be done outside of that job with whatever funding you can cobble together and I certainly have colleagues in a situation where they're having to do that.

\#21, Male Early Career (later in interview)
...The short-term I think, likely scenario is there'll be increased fractionation of current consultants to let more people come in, but with fractionation can become a bit of instability in departments and who is going to take the role of teaching if you're all $0.4 \mathrm{~s}$ and you're all working quite hard clinically and that load, who's going to do that? work were concurrently viewed as integral for both career development and progression, and for good practice (keeping 'up to date'). Thus, the interviews highlighted the paradox of non-clinical activities within contemporary fractional oncology work-the extra pressure to build a career in creative ways, by being involved and engaged with tasks that were increasingly observed as unpaid.

\section{The emerging flexibility of oncology as a speciality, and the} attraction of fractional appointments (for some)

While the difficulties of building a career were talked about at length by participants, we heard mixed accounts of the benefits of fractional appointments. For some participants, fractional work offered the scope to limit clinical work so as to pursue other areas of work of interest, namely research. In this, and other ways, medical oncology was viewed by almost all participants as 'better' than other specialties in terms of flexibility. So too was the specialty talked about as a supportive option for women; most participants perceived a growing number of female trainees within the workforce due to this flexibility (in part enabled by fractional appointments which would be less viable in other specialty areas due to the nature of the clinical work). ${ }^{14}$ However, there was acknowledgement within the interviews of the potential penalties for those engaging in fractional appointments, namely through fewer opportunities for career advancement. ${ }^{1638}$ In addition, fractional appointments as a mode of flexible work were frequently positioned as unfair: either for those occupying the fractional appointment, or for those working full-time around them. This flexibility was positioned by some participants as holding consequences for everyone else, where full-time (or other part-time) employees experienced resentment at needing to pick up extra work to compensate for those working part time (as shown in table 5). Indeed, it was clear from the interviews that while medical oncology was viewed as a flexible specialty, structural disadvantages were perceived to be experienced by some more than others. 
Table 5 Indicative quotations: emerging flexibility of oncology as a specialty

Participant
\#2, Male, Early Career
\#19, Female, Consultant

\section{Indicative quotation}

In terms of I guess what I'm going to be doing [in the future], look, I see myself doing less direct patient clinical work. So at the moment, probably $85 \%$ of my week is direct patient care or activities. l'd probably want to see that down to about $50 \%$. l'd want to be doing a lot more clinical research, particularly focused on regional and rural oncology outcomes. So I see myself really trying to pare back my clinical workload and do more research.

I think within medical oncology it probably, as a whole, is reasonably flexible. So I think medical oncology is probably one of the specialities, I think, that is a lot more open to that than others. I mean when I was training everyone was full-time and it was, it was [laughs] not seen as difficult but there just wasn't the options out there to do fractional work, whereas it is happening a lot more now and it's just a part of life.

\#11, Female, Advanced
trainee

\#7, Male, Consultant

I'm all for maternity leave and feminism and work-life balance and working mums and all that but it just leaves everyone short and that makes it very tiring because you're covering... it just means people who aren't pregnant have to pick up extra work.

Unfortunately, the penalty for that [career advancement through research], it doesn't work for parttime workers. The feminisation of the workforce makes that pretty tough because I work about 80 to 100 hours a week in order to do both [clinical work and research].

\#14, Male, Early Career

I think there's a lot more oncologists that are more comfortable doing point, two or three days a week, as opposed to where l've worked, most of the oncologists have been full-time or part-time oncologist, part-time research academic. But I think...it's a lot more, I guess it's a, pretty women heavy specialty, so there's more acknowledgement that someone working three days a week is still fine.
\#20, Male, Consultant

Certainly the number of female trainee oncologists has increased significantly. When I started [laughs], there was one female oncologist in New South Wales, trainee oncologist, and now the breakdown across the country...It's very close. It's very equivalent. We get a lot of female trainees, and they've seen the opportunity to go off and have families and all that. Certainly, it's encouraged. It does make life a little bit interesting sometimes but it certainly hasn't been a challenge to females coming in. A lot of females do see oncology as being good from a lifestyle because you don't necessarily have to work full time but the opportunity to work in a sort of 0.5-0.6 FTE type position is certainly something that can be done, you know, perhaps it's more of a challenge in other specialties.

\#13, Female, Early Career I think not many women will be taking on $1.0 \mathrm{~s}$, if there were any. Most women would be taking on fractions.
Fractional appointments and 'the healthy triangle': the impacts of fractional as norm on workforce sustainability and quality of care

A final significant theme derived from the interviews was the consequences of fractional appointments, both for workforce sustainability (career security, job satisfaction, avoiding burnout and so on), and also for the quality of care provided to patients. The importance of doctors' engagement in clinical work, research and teaching was flagged by all participants (regardless of their personal level of interest in research or teaching). That is, as one participant put it, the optimal 'healthy triangle' of good doctoring was represented by involvement in teaching and research as well as clinics. Only through such involvement could doctors be adequately equipped to provide quality patient care (through keeping up to date with developments in research and ways of practising). Several participants (as shown in table 6) talked about the negative consequences of fractional work for patient care, as research and teaching development were pushed down the list of priorities, while patient volume in oncology was understood to be intensifying. Investment, contribution and loyalty to the hospital, institution, health service and patients were viewed as potentially being threatened by fractional appointments, namely through decreased motivation to go 'above and beyond' outside of paid work hours. Importantly, the lack of allocated capacity for teaching was flagged as negatively impacting patient care (dearth of services/available doctors), while the lack of engagement with research was flagged as compromising quality (dearth of highly skilled/up to date doctors). We note here that fractional appointments in and of themselves were not viewed as compromising quality care. Rather, that fractional appointments were understood to be dominated by clinic time, thus without capacity for engagement in other professional activities which were viewed as critical for good practice.

\section{DISCUSSION}

The findings in this paper highlight the considerable challenges, as well as benefits, associated with fractional appointments among a sample of Australian medical oncologists, raising a series of questions around the 
changing character of the workforce, particularly for the ways that medical work is performed. The conditions of fractional work, as articulated by our participants, introduce new landscapes of anxiety and uncertainty around job security and longevity, lower pay, less status or visibility, less institutional loyalty, as well as social isolation through lack of collegiality and pressure for non-clinical work to be conducted outside of paid hours. ${ }^{68111214-171939}$ Thus, while forms of fractional work may be attractive for oncologists through offering flexibility, the above conditions may also contribute to clinician fatigue, low morale and burnout, as well as compromising the quality of service provision. ${ }^{12} 212326$ Moreover, the analysis above, and as we have shown elsewhere, ${ }^{14}$ reveals gender as a key dimension within discussion of fractional work, reflecting ongoing debates, for example, related to the likelihood for women to work part time or take more career breaks compared with men, and the consequences for career prospects therein. ${ }^{1416384041}$ The findings in this paper also bolster research that shows the significant potential for negative costs of fractional work (particularly in terms of persistent gender inequality in medicine), despite increasing demands for flexibility. The imperative within medicine to be available and dedicated to working long hours may disadvantage those in fractional work, for example, through limited prospects for promotion. ${ }^{3840-43}$
The paradox of fractional work: flexibility or constraint?

Paradoxically, views on flexibility and individual preferences were combined with accounts of the creation of linearity and intensification, namely through the distinction (and contradiction) between fractional work as flexible work, and fractional work as clinic work. Our findings revealed a divide between the potential attraction of fewer work hours, and the less flexible content of fractional work in practice. In this way, a push towards fractional appointments might actually be viewed as creating more linear, rather than diversified, roles within medical oncology, by repositioning (and narrowing) what is deemed legitimate work within clinical appointments. Fractional appointments (as understood by our participants at least) reflected an intensification of clinic hours and patient load, with less emphasis on research, teaching, mentoring and other non-clinical tasks or roles. ${ }^{24}$

\section{Fractional work as clinic hours and the implications therein}

The implications of fractional appointments focused on clinical work are twofold and interrelated. First, new volunteer roles emerge, where non-clinical tasks (or those previously considered to be part of clinical work) are undertaken outside of paid hours. Second, a form of accelerated medical practice comes to the fore, where there is reduced capacity to develop as a clinician (and person), but also to embark on person-centred approaches to

Table 6 Indicative quotations: fractional appointments and 'the healthy triangle'

\begin{tabular}{ll} 
Participant & Indicative quotation \\
\hline \#7, Male, Consultant & I am really, principally, a public practice doctor with a tiny private practice one afternoon a week. I value \\
& the fact that I'm surrounded by colleagues all the time, of many different disciplines where I can explore \\
& any issue that needs exploring and find someone who's knowledgeable in it at a moment's notice. So I \\
& really don't know what it would be like to not have that. It defines the way I work...the fact that I know \\
I've got people to work with at all times.
\end{tabular}

\#16, Male, Consultant ...new oncologists get employed in a 0.4 capacity and then the rest of the time they do private practice or they do research or they do something else but they don't have the same contribution to the hospital as a full-timer, and that can have negative impact on patient care, on quality of the service and I don't think it's a good thing. But, we like it or not, that's what's happening.

\#10, Male, Consultant This is well known. It's called the healthy triangle you know. Where you get the best care is where the
doctors are engaged in research and teaching because then you will be guaranteed that they will be
right up-to-date, they won't be doing stupid things, they won't be doing something that's gone out of
fashion or out of date. So yeah, it's pretty obvious. If you just sit in your rooms all day and go and do
an outpatients [clinic] twice a week but you're not in, you actually don't know "That's not how you treat
brain metastases anymore. You don't do old brain radiotherapy you know. Haven't you heard about this
combination of using stereotactic radiotherapy with an immunotherapy treatment?" "What? What's all
that about, you know?" How do I know? Well, it's because l'm involved in the clinical trials, I'm in the
research team. It's not just a question of going and sitting up the back of the conference once a year.
You've got to be engaged with it. \#13, Female, Early [In the future] Probably l'd like a fraction at a teaching hospital and have a day or two in the private. The Career fraction with the teaching hospital would come teaching with that. l'd like to continue teaching the med students, the basic registrars, and the senior registrars, and mentoring as well ... yeah, l'd probably say l'd be probably part-time for the next maybe decade with kids and soccer and whatever, which I think is the way of the future.

\#21, Male, Early There's pros and cons of this fractionated system which, unfortunately, I think, for many can mean that Career research and education are dropped down in the pecking order in terms of importance, whereas I would argue that they are fundamentally important and equally important as a medical oncologist. 
medicine and care. This new mode of practice, emerging from neoliberalism and economic rationalism, ${ }^{44}$ shows little consideration for the bigger picture of service provision, care or workforce relations or sustainability. Rather, the emphasis, from an institutional or system perspective at least, narrows towards forms of work (and tasks) that can be easily measured and accounted for (eg, clinic hours, number of patients), ${ }^{45}$ while emphasising the virtues of individual flexibility, choice and entrepreneurial freedom. ${ }^{44}$ Such a climate may be more attractive for some than others, and what may emerge are new forms of privilege and status within the workforce. At the very least, our findings necessitate a timely (re)consideration of the consequences of fractional work for individuals and professions, particularly when work involves such important tasks as doctoring.

\section{Fractional work, (in)stability, and expectations: a social science perspective}

Social scientists have pointed to the dangers of instability in employment, on an individual level (through destabilising a person's identity) and a professional/societal level (by promoting anomie). ${ }^{46}{ }^{47}$ Anomie, a term introduced by sociologist Emile Durkheim, ${ }^{48} 49$ describes the lack of stability experienced by individuals or groups that results from a breakdown or absence of moral or ethical standards or values, or from a lack of ideals or purpose. In the context of medical work with hospitals, a lack of norms in terms of professional expectations for employment and career paths/trajectories may signal considerable danger for personal and professional identity and peer support. The findings in this paper support previous work which has emphasised physician empowerment, engagement, community and institutional commitment as associated with physician well-being and the avoidance of burnout. ${ }^{25} 4750$ A lack of cohesion or collegiality also has consequences for job satisfaction, burnout and service delivery. ${ }^{172123255051}$ Put simply, well-supported and vocationally engaged clinicians (according to our participants, those experiencing the so-called 'healthy triangle' of clinical work, research and teaching) ${ }^{24}$ are likely to be best positioned to provide high-quality care. In turn, clinicians who feel positive about the level of care they are providing have been shown to have greater job satisfaction. ${ }^{15}$ Optimising employment conditions and workplace climate to enable high-quality service provision is critically important within oncology, given increasing patient numbers and treatment volume intensification. ${ }^{2122}$

\section{Study limitations}

Our sample, while appropriate in size for a qualitative study, only captures the experiences of a group of selfselected oncologists, in one Australian state. In addition, our study did not assess the extent to which fractional appointments within public Australian health services are increasing. Thus, while participants described increasing fractional appointments (particularly in place of full-time opportunities), we cannot make claims, based on our findings, related to broad structural increases in fractional appointments in medical oncology. Nor can we provide evidence as to oncologists' views on what might constitute the optimal fraction (for productivity, job satisfaction, patient care and so on), as this was contested and unclear across our participant group. Indeed, for medical oncology, and as has been noted in radiation oncology, ${ }^{52}$ there are little available data in the Australia and New Zealand setting around unemployment and/or underemployment, with most information coming anecdotally from those working at the coalface. Further research is needed to assess whether perceptions of proportional growth in fractional appointments within and outside Australian public hospitals are reflected in practice. Perceptions of the fractional load according to full-time equivalent and type of work also require further research to establish the extent to which part-time jobs are considered attractive, unattractive or constitute underemployment. Finally, award systems and organisational set-up within hospitals vary across (and sometimes within) states and territories in Australia. Further research is needed that takes into account such variation and the implications for experiences of fractional work within and outside medical oncology.

\section{CONCLUSION}

Fractional appointments offer potential flexibility to better suit the needs of the contemporary oncologist, while allowing a greater number of qualified trainees to enter the workforce and gain experience within the public system. However, fractional work also presents challenges in terms of the imperative of professional reinvention. ${ }^{14}$ Our findings suggest a critical juncture in the evolution of the oncological and medical workforce, where traditional understandings and expectations of what one does as, and what it means to be, a medical oncologist, may be shifting; where possibilities and pressures are increasing and changing and where the nexus between job description, physician well-being and patient care comes to the fore, particularly for those entering the workforce. ${ }^{13}$ Medical oncologists face new challenges, new forms of practice and new pathways of career progression. So too are health services tasked with new challenges around managing workforce satisfaction and sustainability at a time of increased patient volume and intensification within cancer care. Future research into the impacts of changing patterns and demands of work on healthcare service delivery is needed to ensure sustainable provision of quality care.

\section{Author affiliations}

${ }^{1}$ Centre for Social Research in Health, UNSW, Sydney, New South Wales, Australia ${ }^{2}$ School of Social and Political Sciences, The University of Sydney, Sydney, New South Wales, Australia

${ }^{3}$ Medical Oncology, Nepean Cancer Care Centre, Nepean Hospital, Penrith, New South Wales, Australia

${ }^{4}$ Sydney Medical School, University of Sydney, Sydney, New South Wales, Australia ${ }^{5}$ Department of Medical Oncology/Haematology, Royal Hobart Hospital, Hobart, Tasmania, Australia 
${ }^{6}$ Cancer Care Services, Royal Brisbane and Women's Hospital, Herston, Queensland, Australia

${ }^{7}$ School of Medicine, University of Queensland, Brisbane, Queensland, Australia

Twitter Emma Kirby @DrEmmaKirby

Acknowledgements The authors thank the study participants who generously offered their time and crucial insight into this research topic. They also thank the Medical Oncology Group of Australia, and in particular Kay Francis for recruitment support and administrative assistance. They also thank and acknowledge WTK Wong for his contribution to fieldwork.

Contributors All authors conceived of and designed the study. EK and $A B$ analysed and interpreted the data. EK, AB and ZL drafted the article; all authors contributed to the development and refining of the article, and approved the final submitted version.

Funding The authors have not declared a specific grant for this research from any funding agency in the public, commercial or not-for-profit sectors.

Competing interests None declared.

Patient and public involvement statement It was not appropriate or possible to involve patients or the public in this work

Patient consent for publication Not required.

Ethics approval This research was performed in accordance with the Declaration of Helsinki. Ethics approval was received from The University of Tasmania Human Research Ethics Committee (Ref: H0014781), and all participants provided written informed consent.

Provenance and peer review Not commissioned; externally peer reviewed.

Data availability statement Data are available upon reasonable request.

Open access This is an open access article distributed in accordance with the Creative Commons Attribution Non Commercial (CC BY-NC 4.0) license, which permits others to distribute, remix, adapt, build upon this work non-commercially, and license their derivative works on different terms, provided the original work is properly cited, appropriate credit is given, any changes made indicated, and the use is non-commercial. See: http://creativecommons.org/licenses/by-nc/4.0/.

\section{ORCID iD}

Emma Kirby http://orcid.org/0000-0001-9754-0342

\section{REFERENCES}

1 Harris MT. Excellence with an edge - practicing medicine in a competitive environment. Gulf Breeze: Fire Starter Publishing, 2010.

2 Draper C, Louw G. Choosing a career in medicine: the motivations of medical students from the University of Cape town. Educ Prim Care 2007:18:338-45.

3 Harris MG, Gavel PH, Young JR. Factors influencing the choice of specialty of Australian medical graduates. Med J Aust 2005;183:295-300.

4 Sivey P, Scott A, Witt J, et al. Junior doctors' preferences for specialty choice. J Health Econ 2012;31:813-23.

5 Eyre HA, Mitchell RD, Milford W, et al. Portfolio careers for medical graduates: implications for postgraduate training and workforce planning. Aust Health Rev 2014;38:246-51.

6 Fundytus A, Sullivan R, Vanderpuye V, et al. Delivery of global cancer care: an international study of medical oncology workload. JGO 2018;4:1-11.

7 de Azambuja E, Ameye L, Paesmans M, et al. The landscape of medical oncology in Europe by 2020. Ann Oncol 2014;25:525-8.

8 Burchell B, Ladipo D, Wilkinson F. Job insecurity and work intensification. London \& New York: Routledge, 2005.

9 Vaswani $\mathrm{N}$, Eyre $\mathrm{H}$, Wang WC, et al. Characteristics of doctors transitioning to a non-clinical role in the MABEL study. Asia-Pac J Public Health 2015;10:33-41.

10 Nancarrow SA, Borthwick AM. Dynamic professional boundaries in the healthcare workforce. Sociol Health IIIn 2005;27:897-919.

11 Lwin Z, Broom A, Sibbritt D, et al. The Australian medical Oncologist workforce survey: the profile and challenges of medical oncology. Semin Oncol 2018;45:284-90.

12 Edwards N, Kornacki MJ, Silversin J. Unhappy doctors: what are the causes and what can be done? BMJ 2002;324:835-8.

13 Wong WKT, Kirby E, Broom A, et al. A mixed methods analysis of experiences and expectations among early-career medical oncologists in Australia. Asia Pac J Clin Oncol 2018;14:e521-7.
14 Broom A, Wong WKT, Kirby E, et al. A qualitative study of medical oncologists' experiences of their profession and workforce sustainability. PLoS One 2016;11:1-15.

15 Halkett GKB, McKay J, Hegney DG, et al. Radiation therapists' and radiation oncology medical physicists' perceptions of work and the working environment in Australia: a qualitative study. Eur J Cancer Care 2017;26:e12511.

16 McMurray J, Linzer M, Konrad T, et al. The work lives of women physicians: results from the physician work life study. J Gen Intern Med 2000;15:372-80.

17 Linzer M, Konrad TR, Douglas J, et al. Managed care, time pressure, and physician job satisfaction: results from the physician worklife study. J Gen Intern Med 2000;15:441-50.

18 Costa G. Shift work and occupational medicine: an overview. Occup Med 2003;53:83-8.

19 Bidwell S, Simpson A, Sullivan R, et al. A workforce survey of new Zealand medical oncologists. N Z Med J 2013;126:45-53.

20 McGilvray A. Doctors of many talents. Med J Aust 2013;199.

21 Raphael MJ, Fundytus A, Hopman WM, et al. Medical oncology job satisfaction: results of a global survey. Semin Oncol 2019;46:73-82.

22 Popescu RA, Schäfer R, Califano R, et al. The current and future role of the medical oncologist in the professional care for cancer patients: a position paper by the European Society for medical oncology (ESMO). Ann Oncol 2014;25:9-15.

23 Girgis A, Hansen V, Goldstein D. Are Australian oncology health professionals burning out? A view from the trenches. Eur $\mathrm{J}$ Cancer 2009;45:393-9.

24 Joyce CM, Piterman L, Wesselingh SL. The widening gap between clinical, teaching and research work. Med J Aust 2009;191:169-72.

25 Murali K, Banerjee S. Let's address burnout in oncologists and reimagine the way we work. Nat Rev Clin Oncol 2019;16:1-2.

26 Shanafelt TD, Raymond M, Horn L, et al. Oncology fellows' career plans, expectations, and well-being: do fellows know what they are getting into? JCO 2014;32:2991-7.

27 Levit L, Smith AP, Benz EJ, et al. Ensuring quality cancer care through the oncology workforce. JOP 2010;6:7-11.

28 Cheng TC, Joyce CM, Scott A. An empirical analysis of public and private medical practice in Australia. Health Policy 2013;111:43-51.

29 Generational differences among oncologists: shaping the future of practice. JOP 2009;5:13-17.

30 Dorsey ER, Jarjoura D, Rutecki GW. Influence of controllable lifestyle on recent trends in specialty choice by US medical students. JAMA 2003;290:1173-8.

31 Bryman A. Social research methods. 4th ed. New York: Oxford University Press, 2012

32 Pope C, Ziebland S, Mays N. Analysing qualitative data. In: Pope C, Mays N, eds. Qualitative research in health care. 3rd edn. Oxford: Blackwell Publishing, 2006: 63-81.

33 Malterud K, Siersma VD, Guassora AD. Sample size in qualitative interview studies. Qual Health Res 2016;26:1753-60.

34 Pope C, Ziebland S, Mays N. Qualitative research in health care: analysing qualitative data. BMJ 2000;320:114-6.

35 Ezzy D. Qualitative analysis. Allen and Unwin: Crows Nest, 2002.

36 Fitzpatrick R, Boulton M. Qualitative research in health care: I. The scope and validity of methods. J Eval Clin Pract 1996;2:123-30.

37 O'Brien BC, Harris IB, Beckman TJ, et al. Standards for reporting qualitative research: a synthesis of recommendations. Acad Med 2014;89:1245-51.

38 Gatrell C. A fractional commitment? part-time work and the materna body. Int J Hum Resour Man 2007;18:462-75.

39 Wong WT, Broom A, Kirby E, et al. What lies beneath? experiencing emotions and caring in oncology. Health 2018:1363459318800168.

40 Kilminster S, Downes J, Gough B, et al. Women in medicine--is there a problem? A literature review of the changing gender composition, structures and occupational cultures in medicine. Med Educ 2007;41:39-49.

41 Roberts JH. The feminisation of medicine. BMJ 2005;330:s13.2-15

42 Ozbilgin MF, Tsouroufli M, Smith M. Understanding the interplay of time, gender and professionalism in hospital medicine in the UK. Soc Sci Med 2011;72:1588-94.

43 De Simone S, Scano C. Discourses of sameness, unbalance and influence: dominant gender order in medicine. Journal of Gender Studies 2018;27:914-27.

44 Harvey D. A brief history of neoliberalism. Oxford: Oxford University Press, 2005.

45 Bevan G, Hood C. What's measured is what matters: targets and gaming in the English public health care system. Public Adm 2006;84:517-38.

46 Sennett R. The corrosion of character: the personal consequences of work in the new capitalism. New York: W.W.Norton, 1998. 
47 Kalleberg AL. Precarious work, insecure workers: employment relations in transition. Am Sociol Rev 2009;74:1-22.

48 Durkheim E. Suicide. London: Routledge, 1952.

49 Merton RK. Bureaucratic structure and personality. Social Forces 1940;18:560-8.

50 West CP, Dyrbye LN, Rabatin JT, et al. Intervention to promote physician well-being, job satisfaction, and professionalism. JAMA Intern Med 2014;174:527-33.
51 Jasperse M, Herst P, Dungey G. Evaluating stress, burnout and job satisfaction in New Zealand radiation oncology departments. Eur $J$ Cancer Care 2014;23:82-8.

52 Leung J, Kariyasawam S, Forstner D, et al. Employment for radiation oncologists in Australia and New Zealand: recent graduates survey of experiences and perspectives. J Med Imaging Radiat Oncol 2018;62:94-101. 